\title{
Analysis of microchannel heat exchanger based on channel geometry
}

\author{
Mohammed Faris Tahasildar and Sachidananda Hassan Krishanmurthy ${ }^{*}$ (D) \\ School of Engineering and IT, Manipal Academy of Higher Education, Dubai 345050, UAE
}

Received: 29 September 2021 / Accepted: 10 February 2022

\begin{abstract}
The use of air conditioning in heating ventilating and air-conditioning (HVAC) industry has risen steadily over the last few decades. The goal of the system is to provide a comfortable indoor environment by the process of removal or addition of heat. There are various systems and components which have been in constant use over the years and have evolved with the needs of the user and the environment too. In this research paper attempt have been made to study microchannel heat exchangers in condenser section of package units. The idea is to see how an increase in cross-sectional area through the microchannel increases the area of heat transfer. The effect of grooved cross-section which results in increase of rate of cooling for a fluid flowing through the channel have been studied. R-32 (Freon Refrigerant) is considered as refrigerant along with water for the study using CFD analysis. Two designs were considered for the study considering circular cross section and the grooved cross section considering the channel geometry. From the results of CFD analysis, it can be stated that grooved cross section has performed better in terms of heat transfer and temperature drop as compared to circular cross section.
\end{abstract}

Keywords: Air conditioning / microchannel heat exchanger / condenser / circular section / grooved section

\section{Introduction}

Microchannel heat exchangers (MCHE) have been in use in different industries for decades now. Their application in the field of HVAC is relatively new compared to other Heat Exchangers. The purpose of a microchannel heat exchanger is to improve the overall heat transfer, which would help to reduce the temperature difference between the air and the Refrigerant [1-5]. Ravigururajan [6] have studied the microchannel surfaces which are employed in high heat flux applications. He developed an experimental setup for testing microchannel heat exchangers considering power input, volume flow rate, quality, and inlet subcooling. He concluded that heat transfer and pressure drop depends on flow quality and mass flux, heat flux and related surface superheat. Koichiro et al. [7] have studied the performance of micro channel heat exchanger on heat transfer behavior and pressure loss. They studied the heat transfer considering silicon chip microchannel and the pressure was compared with the analytical results using three dimensional numerical simulations. They concluded that the microchannel heat exchanger system is sufficient to cool the silicon chip and the system they developed is

\footnotetext{
* e-mail: sachidananda@manipaldubai.com
}

compact as compared to electrical equipment setup. Denkenberger et al. [8] have studied a newly developed microchannel heat exchanger design for low-cost production. They studied the new type named forward conduction welding to develop the prototype. This new type can be used to test counter-flow, crossflow, or parallel-flow type of heat exchangers. They concluded that this prototype can be used with higher effectiveness for the prototype they developed using $28 \mu \mathrm{m}$ thick black low-density polyethylene walls. Xuan et al. [9] have studied the surface roughness in microscale fluid flow. They studied the heat transfer and liquid flow and conducted series of experimental examinations considering microscale fluid flow. They concluded that the surface roughness plays an important role in the laminar flow process in microscale fluid flow and has a significant effect on heat transfer. Tingbo and Yuanlong [10] have studied the pressure drop and heat transfer performance in case of microchannel heat exchangers considering the rib arrangement with circular reentrant cavities. This setup was numerically investigated in ANSYS, and the corresponding experimental platform was designed and built for the verification. They concluded that the pressure drop was increased between the inlet and outlet due to rib structure and heat transfer performance was best for microchannel heat exchangers with circular reentrant cavities. Mushtaq et al. [11] have studied the 
Table 1. Dimensions of header.

\begin{tabular}{|c|c|c|c|c|c|c|}
\hline $\begin{array}{l}\text { Outer } \\
\text { Diameter } \\
(\mathrm{mm})\end{array}$ & $\begin{array}{l}\text { Inner } \\
\text { Diameter } \\
(\mathrm{mm})\end{array}$ & $\begin{array}{l}\text { Length } \\
(\mathrm{mm})\end{array}$ & $\begin{array}{l}\text { Discharge outer } \\
\text { diameter } \\
(\mathrm{mm})\end{array}$ & $\begin{array}{l}\text { Discharge inner } \\
\text { diameter } \\
(\mathrm{mm})\end{array}$ & $\begin{array}{l}\text { Cap design } \\
\text { Outer diameter } \\
(\mathrm{mm})\end{array}$ & $\begin{array}{l}\text { Round and } \\
\text { Depth }(\mathrm{mm})\end{array}$ \\
\hline
\end{tabular}

microchannel heat exchangers considering channels of various geometries to study the effects of thermal and hydraulic performance. They carried out numerical simulations considering 3D flow and 3D conjugate heat transfer and its effect on various channels (Circular, square, rectangular, iso-triangular, and trapezoidal) of microchannel heat exchangers. They concluded that by developing new correlations between heat exchanger effectiveness and performance index. Long et al. [12] have studied the variable tube geometry in case of microchannel heat exchangers. They developed the design concepts of variable geometry in material saving potential in microchannel heat exchangers and investigated the effects of air flow distribution to optimize heat exchanger geometry. They concluded that better performance can be obtained by varying the design geometry as compared to conventional microchannel heat exchanger design. Ooil and Goh [13] have studied the macroscale heat exchangers with microchannel heat transfer capability. Their study is to fabricate macro-scale heat exchangers in case of microchannel heat exchangers which is economical and simple and readily available. They concluded that their developed conventional fabrication techniques can be used in many practical applications in the design of heat exchangers. Ying and Minqiang [14] have studied $\mathrm{N}$-structure in microchannel heat exchangers to study heat transfer performance and pressure drop. They investigated the microchannel heat exchanger by adding a straight channel section to produce the same wavelength as to get the $\mathrm{N}$-structure to study the heat transfer performance. They concluded that pressure drop between the inlet and outlet of cold side is influenced by the structure of microchannel. Ines et al. [15] have studied the numerical approach in case of microchannel heat exchanger to analyze the effect of different geometries. They analyzed the different geometries considering COMSOL Multiphysics and these results were compared with microchannel heat sinks by considering distilled water as the working fluid. They concluded that by increasing the number of channels, there is increase in uniformity of flow designs which improves the heat transfer. Zeynep and Nezaket [16] have studied the cross flow microchannel heat exchanger made of aluminum material considering square microchannels. They have also developed the experimental setup to perform fluid flow and heat transfer measurements. They concluded that the experimental values agreed with the CFD simulation. Canberk et al. [17] have studied thermodynamic performance using R32 in case of residential heating, ventilating and air conditioning system which is an alternative for R410A because of its low global warming potential. They concluded that R32 can be used in variable refrigeration systems as an alternative to R410A. Tri et al. [18] have studied microchannel heat exchanger with S-shaped fins using CFD fluent code to confirm simulation results of thermal hydraulic performance in case of carbon dioxide loop to study the pressure drop made of s-shaped fins and to compare with the conventional with zigzag films. They concluded that the experimental results were in line with the standard deviation of 13 to 16 percent. Nikkah and Nakhjavani [19] have studied water- based nanofluid in a micro-heat exchanger for microelectronic cooling application. They studied considering nano-fluids at various mass concentration to measure thermal conductivity, heat capacity, density and viscosity using experimental method. They concluded that heat transfer coefficient was enhanced with improvement in thermal conductivity and the pressure drop was increased due to increase in the viscosity of the working fluid. From the above literature review it is observed that authors have studied various microchannel heat exchangers considering channel geometry, different material etc. So, in this research work attempt have been made to study microchannel heat exchanger considering circular and grooved cross section geometry.

\section{Methodology}

The micro-channel was designed using CREO software (Computer aided design software) and the analysis have been performed in ANSYS workbench. The dimensions considered for the microchannel heat exchanger were based on actual dimensions used in industry by scaling down with a scale factor of 4:1.

Heat transfer rate (watt) was calculated using the following equation given below.

$H=m C_{p} \Delta T=m C_{p}\left(T_{i}-T_{O}\right)$ Where $T_{i}$ and $T_{o}$ is the inlet and outlet temperature in degree centigrade, $\mathrm{m}$ is the mass flow rate $=0.5 \mathrm{~kg} / \mathrm{m}^{3}$ and $C_{p}$ is the specific heat at constant pressure (for water $4.184 \mathrm{~kJ} / \mathrm{kg} \mathrm{K}$ and for $\mathrm{R} 32$ $0.84 \mathrm{~kJ} / \mathrm{kg} \mathrm{K})$.

\subsection{Header}

The purpose of the header is to distribute the refrigerant to the channels. In addition to proper sizing of the header manifolds, it is essential to determine the optimal insertion length of the microchannel tube into the header during the header/tube assembly process. The dimensioning and scaling of the main header are as shown in Table 1. 


\subsection{Refrigerant Tube}

Microchannel flat tubes, which may improve the refrigerant side heat transfer coefficient and minimize air-side flow resistance and contact thermal resistance between flat tube and aluminum fins, are used in refrigerant tubes to boost heat transfer capacity. The corresponding dimension of channel diameter, length and width is equal to $1.5 \mathrm{~mm}$, $30 \mathrm{~mm}$, and $2 \mathrm{~mm}$.

\subsection{Fins}

Fin heat exchanger cells have been constructed which can withstand high internal pressures and temperatures while maintaining the thermal strain-compliance benefits. A matrix of extended heat transfer surfaces in the form of densely packed folding fins brazed within an exterior shell is used in these cells. The corresponding header dimension (3D modelling), side view, refrigerant tube, top view, fin geometry, fin perspective view and assembled perspective view is as shown in Figure 1.

\subsection{Analysis and design}

The grooved and circular microchannel geometry is considered for the study in case of microchannel heat exchangers for comparison purposes. The corresponding isometric view of the grooved and circular microchannel geometry is as shown in Figure 2. With the application of this geometry, it is possible to observe the increase in heat transfer.

\subsection{Finite element analysis}

The boundary conditions set for the analysis are as follows and the corresponding changes in scale of $4: 1$ in terms of boundary conditions have been incorporated in the study. The study includes the design of microchannel heat exchanger and the material have been considered which yields better results for the analysis. It Consists of Inlet Temperature of fluid $\left(\mathrm{T}_{\mathrm{IF}}\right)$, Inlet Temperature of Air $\left(\mathrm{T}_{\mathrm{IA}}\right)$, Inlet Velocity of Fluid $\left(\mathrm{V}_{\mathrm{IF}}\right.$, Inlet Velocity of Air ( $\mathrm{V}_{\mathrm{IA}}$ ), Refrigerant (Water or R-32 (is an Freon Refrigerant), Channel Geometry (Circular or Grooved) and Material (Aluminum and Copper).

Based on the above listed parameters, Finite Element Analysis will be performed on the model. The aim is to see with which combination of the configuration and parameters applied is possible to get the better performance in the above conditions as mentioned in Tables 2 and 3 .

Figure 3 shows the temperature gradient of water and water tube considering aluminum [20,21] as the material. This analysis is done by considering the circular groove cross section. From this analysis it can be observed that the maximum temperature of water is $3.690 \mathrm{e}+002 \mathrm{~K}$ and water tube is $3.608 \mathrm{e}+002 \mathrm{~K}$. The amount of heat transfer taking place in this case is $2.717 \mathrm{~W}$.

Figure 4 shows the temperature gradient for water and water tube considering circular groove cross section for copper. From this analysis it can be observed that the maximum temperature encountered is $3.69 \mathrm{e}+002 \mathrm{~K}$ and $3.607 \mathrm{e}+002 \mathrm{~K}$ for water and water tube respectively.

Figure 5 shows the temperature gradient for water and reference tube considering aluminum and grooved cross section. From this Figure 5 it is observed that the maximum temperature is $3.695 \mathrm{e}+002 \mathrm{~K}$ and $3.657 \mathrm{e}+002 \mathrm{~K}$ for water and reference tube respectively. The heat transfer rate taking place in this case is $7.106 \mathrm{~W}$. From this it is observed that the rate of heat transfer taking place in case of grooved (aluminum) cross section [22,23] is more as compared to circular cross section (aluminum). From this analysis it is understood that the heat transfer is more in grooved cross section. Figure 6 shows the temperature gradient for grooved cross section considering copper as the material. From this figure it is observed that the maximum temperature encountered is $3.695 \mathrm{e}+002 \mathrm{~K}$.

Figure 7 shows the temperature gradient for refrigerant R32, for aluminum and grooved cross section. From this Figure 7 it is observed that the maximum temperature gradient is $3.380 \mathrm{e}+002 \mathrm{~K}$ and $3.158 \mathrm{e}+002 \mathrm{~K}$ for $\mathrm{R} 32$ and reference tube. The amount of heat transfer taking place in case of this arrangement is $9.922 \mathrm{~W}$. In this case the amount of heat transfer rate is more as compared to all other cases considered. Figure 8 shows the temperature gradient for refrigerant R32 (Circular cross section) for Aluminum material. From this it is observed that the maximum temperature is $3.3802 \mathrm{e}+002 \mathrm{~K}$. Table 4 shows the sample comparison table for grooved and circular cross section for aluminum considering water and R32 refrigerant. From this Table 4 it is observed that comparison is given only for aluminum material as aluminum has performed better as compared to copper material and hence copper was not considered for further analysis.

\section{Conclusions}

In this research paper an attempt has been made to study the heat transfer in case of microchannel heat exchangers considering circular and grooved cross section geometry. This analysis has been carried out using ANSYS software considering water and R32 refrigerant. The following conclusions can be drawn from the above study.

- From the microchannel heat exchanger considering channel geometry, it is observed that grooved cross section provides more heat transfer as the surface area is more as compared to circular cross section. The heat transfer rate observed was $7.106 \mathrm{~W}$ in case of grooved cross section considering water as refrigerant.

- The heat transfer rate observed is $9.922 \mathrm{~W}$ for grooved section considering R32 refrigerant. From this it can be concluded that high heat transfer rate in case of grooved cross section was observed when R32 was used in case of microchannel heat exchangers and the corresponding temperature drop is also more as compared to water when used as refrigerant.

- From these results, it is evident that R-32 as a refrigerant can provide much better results in comparison with 


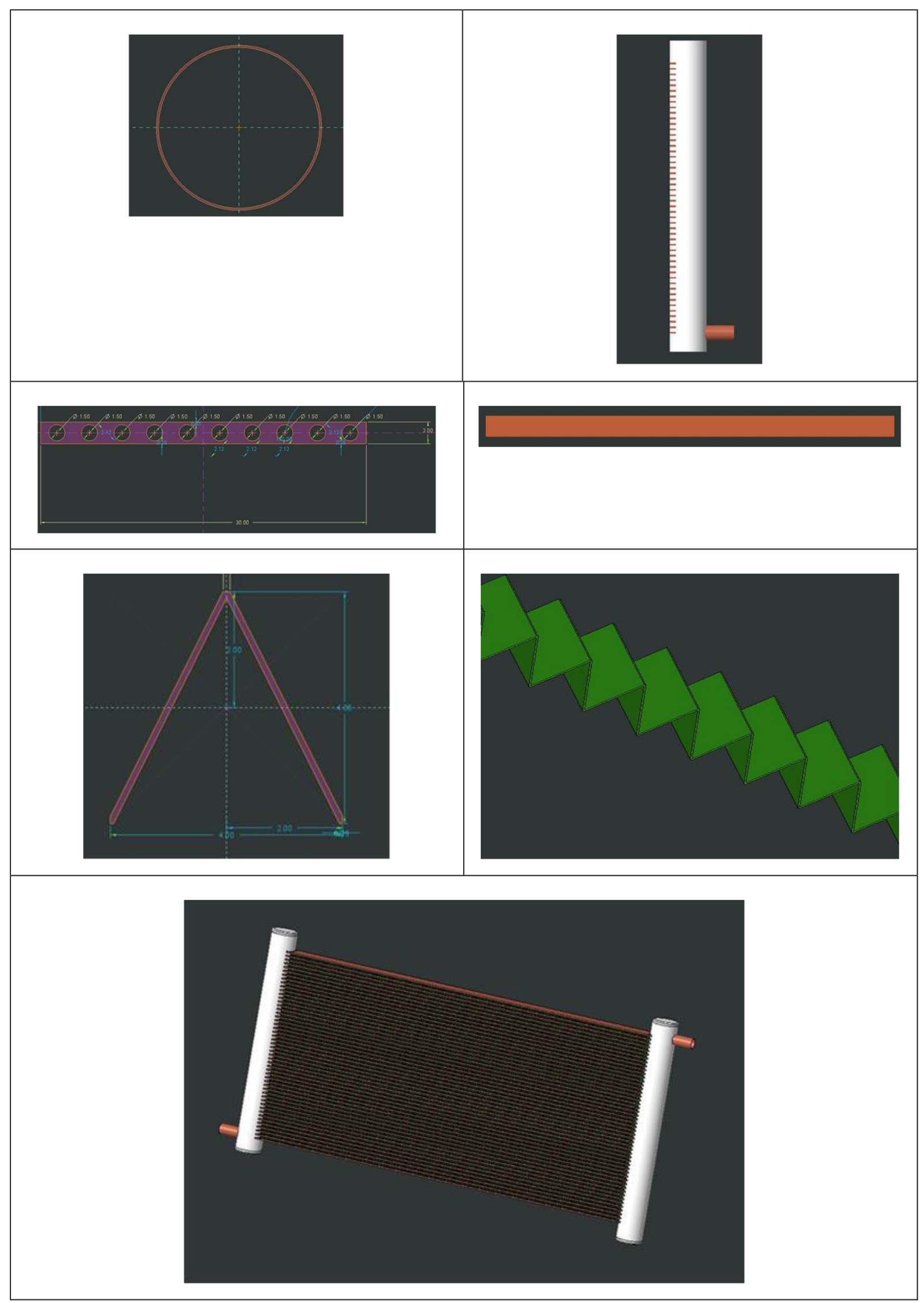

Fig. 1. Main header dimensions, header side view, refrigerant tube, refrigerant top view and fin geometry, fin perspective view and assembled perspective view. 

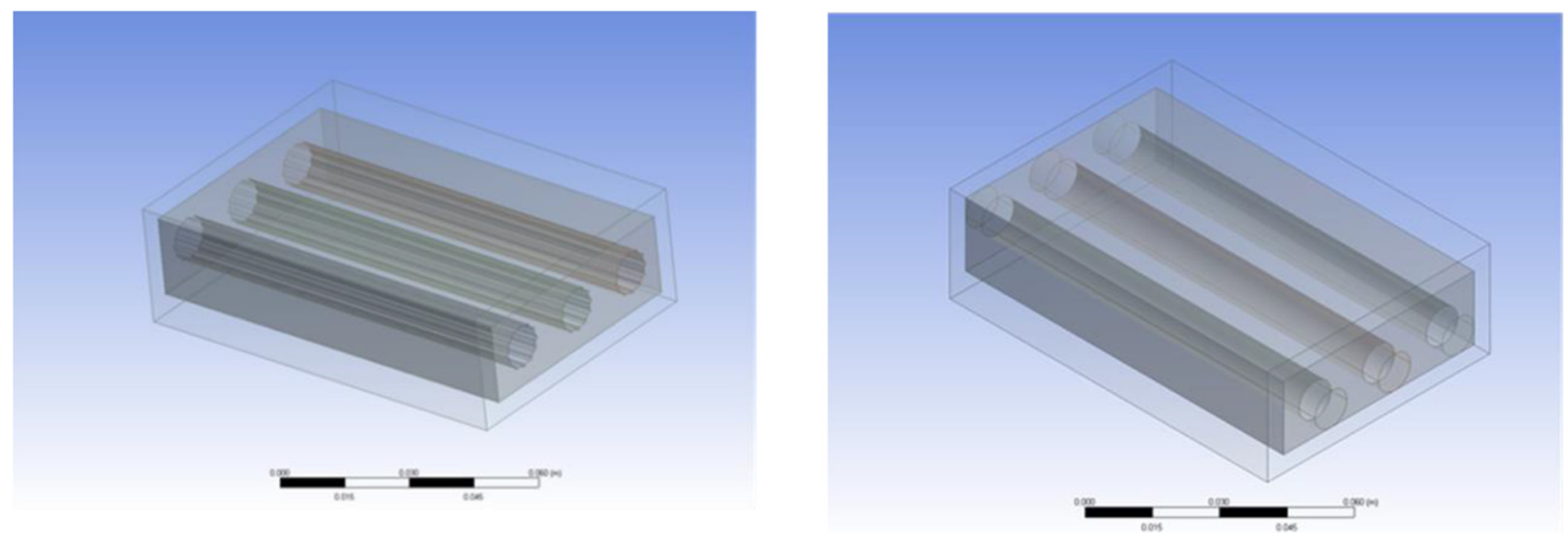

Fig. 2. Grooved and circular microgeometry cross section.

Table 2. Boundary conditions for water- 1 and water- 2 .

\begin{tabular}{lll}
\hline Boundary Condition & Temperature, Material and Channel & Temperature, Material and Channel \\
\hline $\mathrm{T}_{\mathrm{IF}}$ & $369 \mathrm{~K}$ & $369 \mathrm{~K}$ \\
$\mathrm{~T}_{\mathrm{IA}}$ & $300 \mathrm{~K}$ & $300 \mathrm{~K}$ \\
$\mathrm{~V}_{\mathrm{IF}}$ & $0.25 \mathrm{~m} / \mathrm{s}$ & $0.25 \mathrm{~m} / \mathrm{s}$ \\
$\mathrm{V}_{\mathrm{IA}}$ & $10 \mathrm{~m} / \mathrm{s}$ & $10 \mathrm{~m} / \mathrm{s}$ \\
Material Used & Aluminum & Copper \\
Type of Channel & Circular/Grooved & Circular/Grooved \\
\hline
\end{tabular}

Table 3. Boundary Conditions for R32-1 and R32-2.

\begin{tabular}{lll}
\hline Boundary Condition & Temperature, Material and Channel & Temperature, Material and Channel \\
\hline $\mathrm{T}_{\mathrm{IF}}$ & $338 \mathrm{~K}$ & $338 \mathrm{~K}$ \\
$\mathrm{~T}_{\mathrm{IA}}$ & $308 \mathrm{~K}$ & $308 \mathrm{~K}$ \\
$\mathrm{~V}_{\mathrm{IF}}$ & $10 \mathrm{~m} / \mathrm{s}$ & $10 \mathrm{~m} / \mathrm{s}$ \\
$\mathrm{V}_{\mathrm{IA}}$ & $4 \mathrm{~m} / \mathrm{s}$ & $4 \mathrm{~m} / \mathrm{s}$ \\
Material Used & Aluminum & Copper \\
Type of Channel & R-32 & R-32 \\
\hline
\end{tabular}
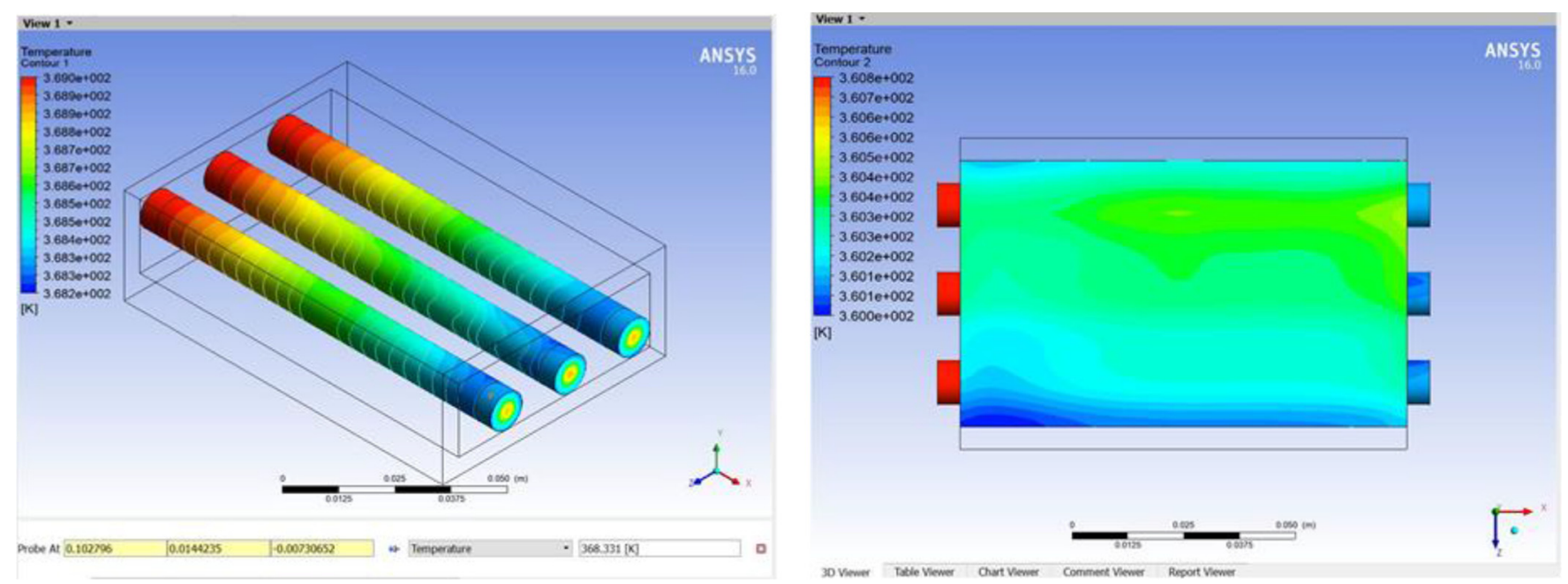

Fig. 3. Temperature gradient of water and water tube - aluminum (circular groove). 

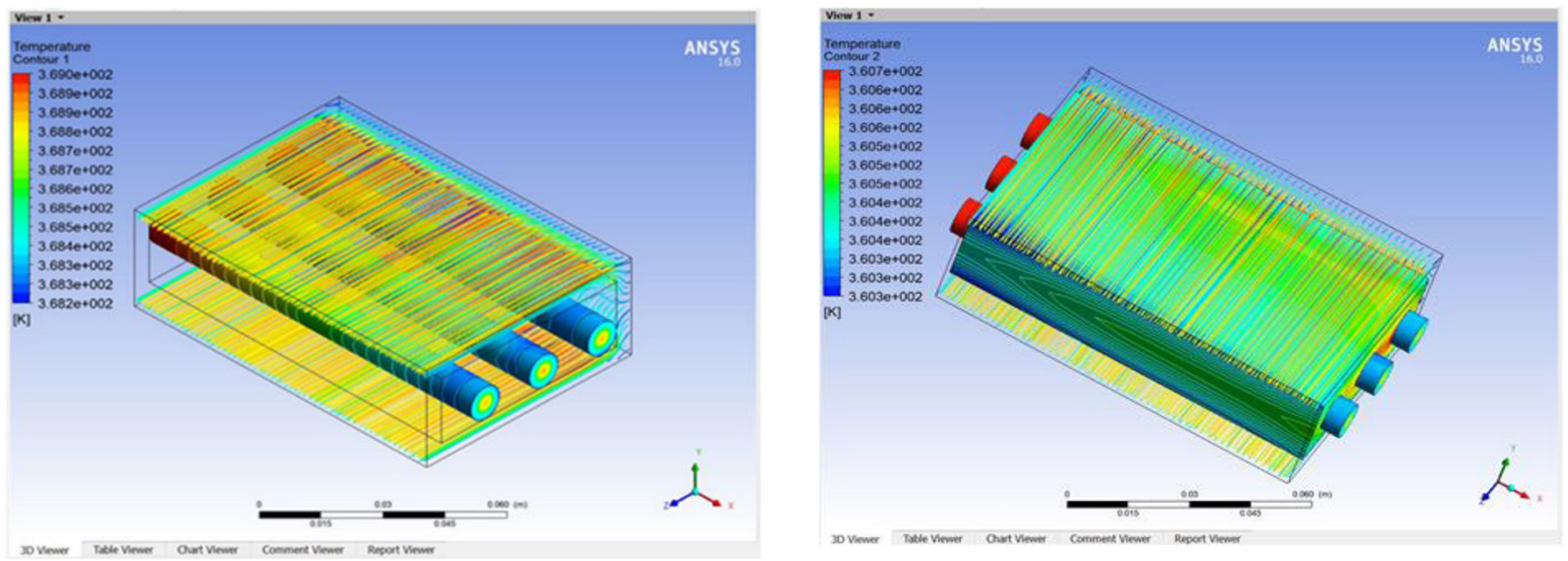

Fig. 4. Temperature gradient of water and reference tube - copper (circular groove).
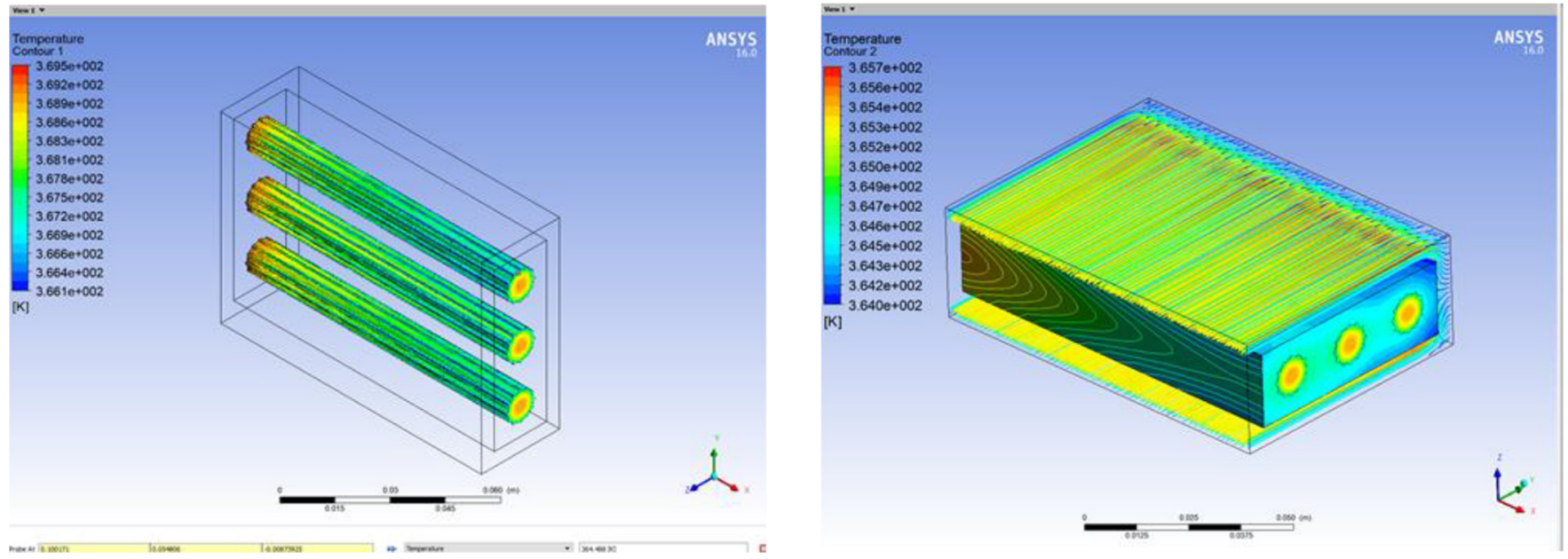

Fig. 5. Temperature gradient of water and reference tube - aluminum (grooved).

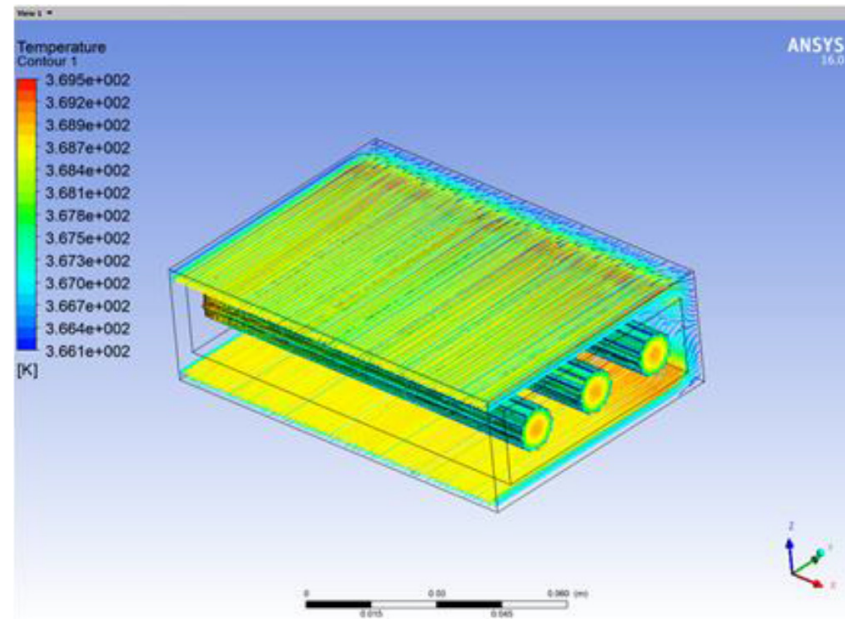

Fig. 6. Temperature gradient of water and reference tube - copper (grooved). 

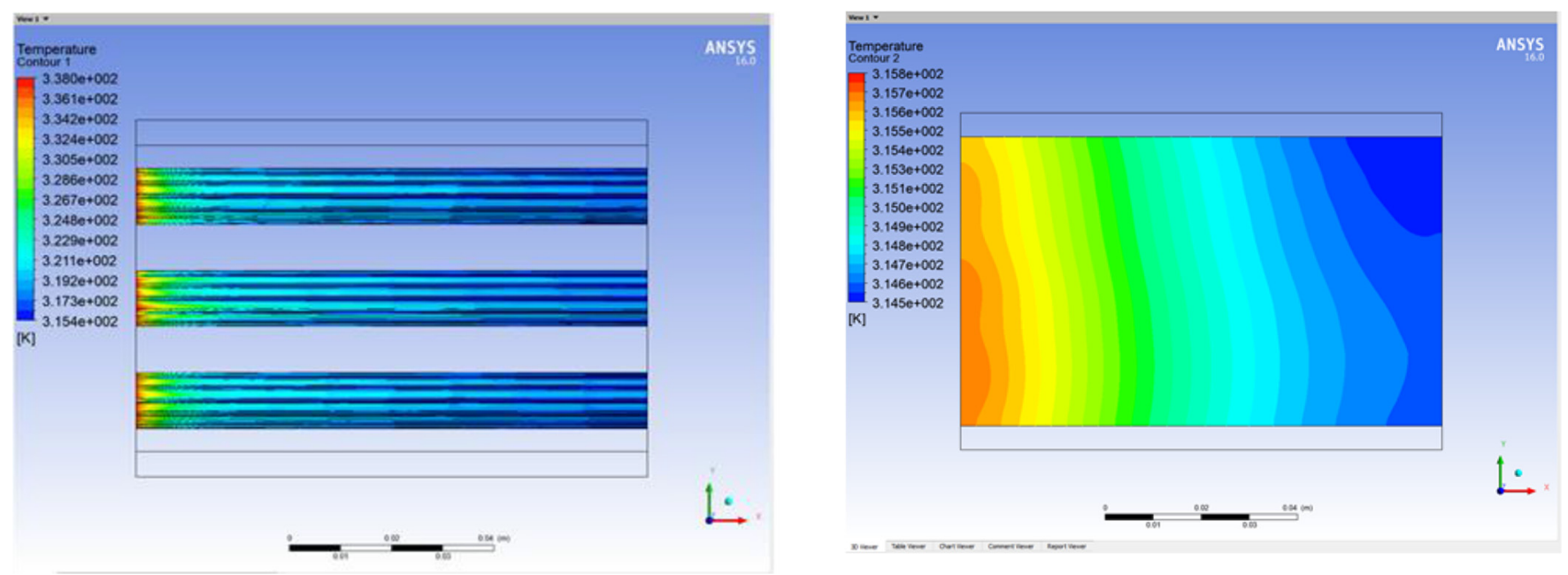

Fig. 7. Temperature gradient for R-32-aluminum (grooved).

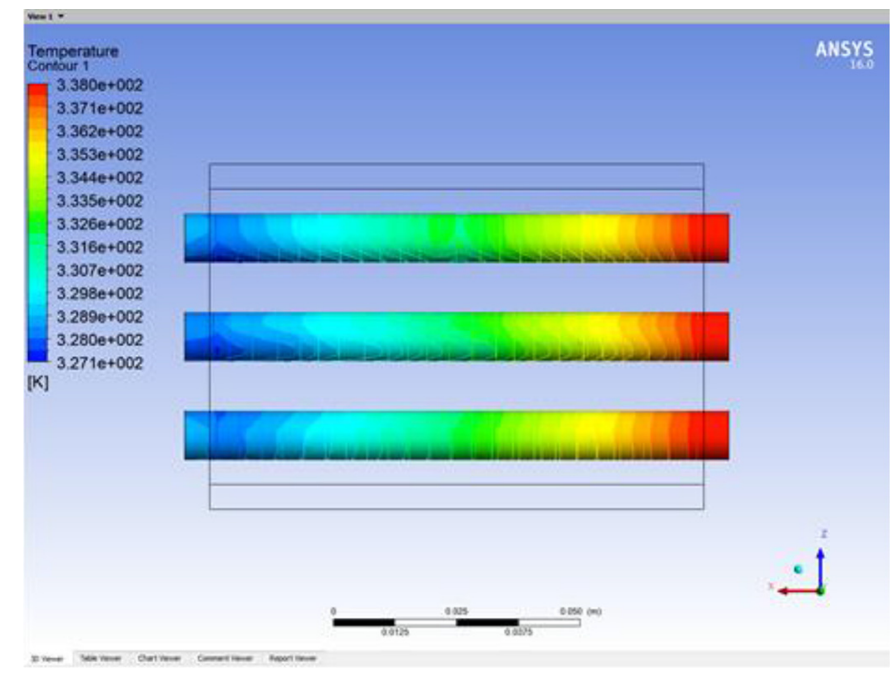

Fig. 8. Temperature gradient of R-32, aluminum (circular groove).

Table 4. Results of CFD analysis.

\begin{tabular}{lllll}
\hline Geometry & Material & Inlet temperature $(\mathrm{K})$ & Outlet temperature $(\mathrm{K})$ & Heat transfer $(\mathrm{H})$ in Watts \\
\hline Circular (Water) & Aluminum & $369.5 \mathrm{~K}$ & $368.2 \mathrm{~K}$ & $2.717 \mathrm{~W}$ \\
Circular (R-32) & Aluminum & $338.5 \mathrm{~K}$ & $327.1 \mathrm{~K}$ & $4.834 \mathrm{~W}$ \\
Grooved (Water) & Aluminum & $369.5 \mathrm{~K}$ & $366.1 \mathrm{~K}$ & $7.106 \mathrm{~W}$ \\
Grooved (R-32) & Aluminum & $338.5 \mathrm{~K}$ & $315.1 \mathrm{~K}$ & $9.922 \mathrm{~W}$ \\
\hline
\end{tabular}

Water as refrigerant. This attributed due to increase in area of heat transfer and furthermore, improving the Heat Transfer rate in a Grooved Cross-section of Channel Geometry.

\section{References}

1. Y.H. Han, Y.L. Ming Li, J. Huang, Review of development of Micro-channel heat exchanger applied in air-conditioning system, Energy Proc. 14, 148-153 (2012)
2. Y. Fan, L. Luo, Recent applications of advances in microchannel heat exchangers and multiscale design optimization, Heat Transfer Eng. 29, 461-474 (2011)

3. M.G. Khan, A. Fartaj, A review on microchannel heat exchangers and potential applications, Int. J. Energy Res. 35, 553-582 (2011)

4. A. Dewan, P. Srivatsava, A review of heat transfer enhancement through flow disruption in a microchannel, J. Thermal Sci. 24, 203-214 (2015)

5. E. Zanetti, M. Azzolin, S. Bortolin, B. Giulio, D. Del, Design and testing of a microchannel heat exchanger working as 
condenser and evaporator, Int. Refriger. Air Condit. Conf. July 9-12 (2018) 1-10

6. T.S. Ravigururajan, Impact of channel geometry on two-phase flow heat transfer characteristics of refrigerants in microchannel heat exchangers, J. Heat Transfer 120, 485-491 (1998)

7. K. Kawano, M. Sekimura Ko, M. Hideo, I.M. Ishizuka, Development of Micro channel heat exchanging, JSME Int. J. Ser. B 44, 592-598 (2001)

8. D.C. Denkenberger, M.J. Brandemuehl, J.M. Pearce, J. Zhai, Expanded microchannel heat exchanger: design fabrication, and preliminary experimental test, Proc. Inst. Mech. Eng. A 226, 532-544 (2012)

9. X. Zhang, T. Zhao, S. Wu, F. Yao, Experimental study on liquid flow and heat transfer in rough microchannels, Adv. Condens. Matter Phys. 2019, 1-9 (2019)

10. T. Hou, Y. Chen, Pressure drop and heat transfer performance of microchannel heat exchangers with circular reentrant cavities and ribs, J. Heat Transfer 142, 1-11 (2020)

11. M.I. Hasana, AA. Rageba, M. Yaghoubib, H. Homayoni, Influence of channel geometry on the performance of a counter flow microchannel heat exchanger, Int. J. Thermal Sci. 48, 1607-1618 (2009)

12. L. Huang, V. Aute, R. Radermacher, Design optimization of variable geometry microchannel heat exchangers, in 15th International refrigeration and air conditioning conference at Purdue University, Indiana, July 14-17 (2014)

13. K.T. Ooil, A.L. Goh, Enhanced microchannel heat transfer in macro-geometry using conventional fabrication approach, 7th European thermal science conference (Eurotherm 2016), J. Phys. Conf. Ser. 745, 1-8 (2016)

14. Y. Zhang, M. Pan, Impact of N-structure geometry on heat transfer in a microchannel heat exchanger, Chem. Eng. Technol. 44, 690-697 (2021)
15. I.M. Goncalves, C. Rocha, R.R. Souza, G. Coutinho, J.E. Pereira, A.S. Moita, A.L.N. Moreira, R. Lima, J.M. Miranda, Numerical optimization of a microchannel geometry for nanofluid film and heat dissipation assessment, Appl. Sci. 11, $2440(2021)$

16. Z.K. Meral, N. Parlak, Experimental research and CFD simulation of cross flow microchannel heat exchanger, J. Therm. Eng. 7, 270-283 (2021)

17. C. Yildirim, D. Burcu, O.C. Onan, Theoretical study of R32 to replace in variable refrigerant flow systems, Int. J. Ambient Energy 39, 87-92 (2016)

18. T.L. Ngo, Y. Kato, K. Nikitin, T. Shizuka, Heat transfer and pressure drop correlations of microchannel heat exchangers with S-shaped and Zigzag fins for carbon dioxide cycles, Exp. Thermal Fluid Sci. 32, 560-570 (2007)

19. V. Nikkah, S.H. Nakhjavani, Thermal performance of a micro heat exchanger (MHE) working with Zirconia-based nanofluids for industrial cooling, Int. J. Ind. Chem. 10, 193-204 (2019)

20. A. Uday Kumar, A. Javed, S.K. Dubey, Material selection for microchannel heatsink: conjugate heat transfer simulation, IOP Conf. Ser. Mater. Sci. Eng. 346, 1-8 (2018)

21. O. David, T. Ariyo Bello-Ochende, Constructional design of subcooled microchannel heat exchangers, Int. J. Heat Mass Transfer 146, 118835 (2020)

22. K. Bilen, M. Cetin, H. Gul, T. Balta, The investigation of groove geometry on heat transfer for internally grooved tubes, Appl. Therm. Eng. 29, 753-761 (2018)

23. S. Basavarajappa, G. Manavendra, S.B. Prakash, A review on performance study of finned tube heat exchanger, international conference on thermo-fluids and energy systems, J. Phys. Conf. Ser. 1473, 1-12 (2020)

Cite this article as: Mohammed Faris Tahasildar, Sachidananda Hassan Krishanmurthy, Analysis of microchannel heat exchanger based on channel geometry, Int. J. Simul. Multidisci. Des. Optim. 13, 14 (2022) 